E.L.U.A., 8, 1992, pp: 67-83

\title{
SOBRE REPETICION LÉXICA Y SINTAXIS PREPOSITIVA
}

\author{
JoAQUÍN GARCÍA-MEDALL \\ (Universidad de Valladolid)
}

\begin{abstract}
RESUMEN
This study intends to describe the functions of the Spanish structures whose nouns appear repeated and integrated by means of some connecting preposition, for example de casa en casa $(\mathrm{Pr}+\mathrm{N}+\mathrm{Pr}+\mathrm{N})$, entre cigarro y cigarro $(\mathrm{Pr}+\mathrm{N}+\mathrm{cop} .+\mathrm{N})$ or codo con codo $(\mathrm{N}+\mathrm{Pr}+\mathrm{N})$. Far for confirming fixed schemes, we propose to defend here that there exist very concrete choices of nouns sensitive to this syntactic configuration. They include numerais and continuous nouns referring to parts of the human body, parts of a whole, and place references. Despite the repetition of signs the referential distinction is manintained. In accord with the changes of the nexi the focus is the number limited to 2 , or else an unlimited or presupposed number. But in whatever way indetermined, the said prepositive structures are opposed functionally and semantically to other repetitive structures that are not prepositive. These latter will not be treated in this analysis but nevertheless need a syntax of paratactic coordination and of juxtaposition.
\end{abstract}

\section{1.- ESTUDIOS SOBRE LA REPETICIÓN LÉXICA}

Salvo contadas descripciones de algunos fenómenos de repetición léxica considerados propios del español coloquial, (Beinhauer, 1964/1985) o la enumeración de algunos sintagmas preposicionales con sustantivos repetidos (Morera Pérez, 1988), los estudiosos de esta lengua no han tratado la repetición léxica sino como un fenómeno marginal, bien por su carácter semifraseologizado (González Ollé, 1979), «expresivo» (Pharies, 1983) o simplemente «afuncional» o «enfático». Sin embargo, desde la publicación del excelente artículo de Moravcsik (1978) sobre las reduplicaciones en muchas lenguas y su relación con los sistemas cuantificadores, y del trabajo revelador de Knowles (1979) sobre el comportamiento de las iteraciones léxicas del inglés en estructuras no prepositivas, inexplicables desde un planteamiento generativista, parecía inevitable que se despertara un interés creciente sobre la cuestión. 
En parte esto se ha producido en lenguas de nuestro entorno como el francés, con el libro de Frédéric (1985), de inspiración retórica, y con el artículo de Shapira (1988) sobre la repetición o redoblamiento léxico en esta misma lengua. Otros autores han estudiado los procedimientos de intensificación del italiano (Rainer, 1982), y del italiano y del inglés conjuntamente (Wierzbicka, 1986). En lenguas no tan próximas, y siempre como ejemplificación de la inadecuación teórica de la GGT, Gil (1988) estudia la repetición léxica del georgiano y la relaciona con un complejo sistema de distribución entre referentes.

Hemos de suponer que para hablar de repetición léxica sería necesario llevar a cabo una taxonomía, siquiera parcial, de todos los tipos que en una lengua como el español se pueda hallar. Pero ni siquiera existe coincidencia entre los autores sobre el concepto mismo de repetición o reiteración. De modo que se habla tanto de aquella que afecta meramente a los morfemas (Pharies, 1983, Manteca, 1987), de palabras repetidas (Shapira 1988, Wierzbicka, 1986), de los sintagmas fraseologizados y con variantes morfológicas (González Ollé, 1979), de sintagmas simétricos y cláusulas ecuativas (Beinhauer, 1964/1985), de auténticas proformas de la coherencia textual, como los clíticos (Bernárdez, 1982), e incluso de las repeticiones que tienen como fin la aclaración del sentido en el turno de habla, o relanzamientos (McLaughlin, 1984). Que la repetición pueda describirse, sin embargo, casi en relación con todas las unidades (e incluso los niveles) de la gramática de las lenguas, no nos dice mucho sobre sus funciones en sintagmas particulares.

Las categorías léxicas mayores se integran en la sintaxis prepositiva del español también mediante repeticiones. La hipótesis predice que el sustantivo repetido remite a la cualidad y/o a la intensificación si carece de nexo (Es un hombre hombre/), a la distribución (ya determinada o indeterminada) si lo tiene y es preposicional ( $V$ a de casa en casa/Lo bebió gota a gota), y a la cuantificación indeterminada y a la duratividad si tiene nexo preposicional y coordinación copulativa o bien sólo coordinación copulativa (Le esperó durante horas y horas/ leía y leía). Por regla general, admitimos que los sintagmas preposicionales de la repetición léxica inciden en la distribución, mientras que los sintagmas coordinados perfilan la cuantificación indeterminada, si bien sus determinaciones semánticas tienden a solaparse en ciertas situaciones.

La pretensión de este trabajo es la de describir el funcionamiento de algunos tipos de sintagmas de esta lengua que establecen paradigmas de la distribución y cuantificación a partir de núcleos que se repiten formalmente, pero no referencialmente. Dichos sintagmas son de tres tipos: los de estructura /preposición $+\mathrm{L}$ (que vale por lexema) + preposición $+\mathrm{L} /$, donde $\mathrm{L}$ tiene identidad formal; los de estructura $/ \mathrm{L}+$ preposición $+\mathrm{L} /$, con la misma repetición formal del lexema; $y$, finalmente, los de estructura /preposición $+\mathrm{L}+\mathrm{y}+\mathrm{L} /$ Son, pues, objeto de nuestro estudio sintagmas marcados por relaciones preposicionales entre lexemas repetidos, del tipo/de casa en casa/y /paso a paso/o /año tras año/ , así como sintagmas preposicionales con núcleos idénticos coordinados mediante $y$, como/entre copa y copa/o/durante horas y horas/. Marginalmente, y sin que 
entremos más que someramente en el tema, opondremos estos sintagmas a la repetición léxica de la coordinación y la yuxtaposición.

\section{2.- SOBRE OTROS TIPOS DE REPETICIÓN LÉXICA}

Sin embargo es evidente que no son estas las únicas estructuras repetidas en español. Un escaso corpus mostraría, probablemente, que la repetición léxica en esta lengua focaliza tanto sustantivos continuos o discontinuos /Quiero café café/, /Es una hembra, hembra/; adjetivos /Parece bueno bueno/; sustantivos cuantificados y coordinados por la conjunción copulativa /Comenzaron a caer huevos y más huevos/; verbos coordinados de esa manera /El timbre sonaba y sonaba/; coordinados en mera yuxtaposición /Y yo, que mudo no soy, hablaba, hablaba.../, e incluso verbos repetidos, coordinados y, el segundo de ellos, prefijado con re-y/o con des-, del tipo/Busca y rebusca por los cajones/, /Las nubes se hacen y deshacen en el cielo/, etc. Y ello por lo que respecta a las categorías léxicas principales, puesto que la nómina parece extenderse a adverbios de muchos tipos /Se marchó lejos lejos/, /Siempre quiere más y más/, e incluso a interjecciones, como /iVaya, vaya!/ o /iCaramba, caramba!/.

No habría que olvidar tampoco un tercer grupo no menos importante, pero tal vez más difícil de analizar sintácticamente. Nos referimos a estructuras como/le pese a quien le pese/ o /caiga quien caiga/. De modo arbitrario venimos a denominarlas simétricas, aunque en rigor el eje de su simetría puede mostrar una variedad formal y funcional sorprendente:/pase lo que pase/, /las ponga como las ponga/, /caiga el que caiga/,/vaya uno adonde vaya/, /lo exija quien lo exija/. Y si las anteriores repeticiones tienen un carácter clausular reconocido y una proyección sintáctica (al menos) oracional, algo parecido habría que decir de /Si me descubren, que me descubran/, y, con orden resaltado/Oler, sí huelen mejor las rosas, pero todo el mundo sabe que es una flor muy cara/.

Pues bien, no se han agotado todos los tipos de repetición léxica de las categorías mayores del español. Se dan las oraciones ecuativas puras, del tipo / Un día es un día/,/Algo es algo/,/Los negocios son los negocios/, tanto como las impersonales de objeto repetido y coordinado, como /Porque hay promesas y promesas/, /Hay trabajos y trabajos/, etc. Faltarían aún repeticiones aclarativas, como /Entregarse? ¿Ha dicho usted entregarse?/ - Sí /-¿Pero entregarse de entregarse?/, y otras más cuya sola descripción bien merece una monografía.

\section{3.- PREMISAS PARA EL ESTUDIO DE LA REPETICIÓN EN SSPP}

A la hora de estudiar los sintagmas a que aludíamos al comienzo de estas líneas, resulta claro que una sistematización de las repeticiones en los sintagmas prepositivos debe exigir, como mínimo: 
a) una coherencia interna con el sistema prepositivo del español (un cierto tipo de relaciones, y no otras, establecidas en el seno de sintagmas configurados preposicionalmente);

b) una coherencia icónica general derivada del hecho de la identidad de los signos que intervienen, y basada en la hipótesis de que la repetición léxica debe ser significativa, funcional e integrada sintácticamente, por más que parezca redundante y no informativa;

c) una coherencia paradigmática, que permita que ciertos tipos de sustancias léxicas accedan a configurar núcleos repetidos y puedan sustituirse significativamente.

Allí donde se mantenga sólo alguno o algunos de dichos requisitos no podremos hallar un sistema de las estructuras prepositivas, sino más bien unidades fraseológicas, modismos o expresiones idiomáticas. En lo que atañe a /estar de bote en bote/- /estar de par en par/,/mirar de hito en hito/, donde López (1984/1990:203) interpretaría un esquema «elemento potencialmente variable + elemento idjomático único», y además habría un conector o nudo «k», explicitado formalmente por de. Paralelamente, lo que ocurre con / no...nada de nada/ es que nos encontraremos con un esquema de la modalidad o la performatividad: en ausencia de la negación la expresión idiomática se torna imposible: /Me gusta nada de nada*/. Es lo que Bosque (1980) consideraría una negación fuerte por antonomasia. De haber defectividad en la elección léxica, no serán posibles sustituciones de L, como es el caso de /Lo hacía poco a poco/, pero no /Lo hacía bastante a bastante*/o /mucho a mucho*/.

\section{I.- EL SINTAGMA pr. $+\mathrm{L}+$ pr. $+\mathrm{L}($ de ciudad en ciudad $)$}

\section{Los esquemas formales del sintagma $(p r .+L+p r .+L)$}

a) Desde el punto de vista formal este sintagma se define porque exige como preposición traslaticia a de y porque la nexual puede ser rellenada por en o por $a$. Ambas preposiciones pueden hallarse en distribución complementaria en ciertos casos. En lo relativo a $L$, es este un sustantivo o sustantivado que siempre debe encontrarse en singular. Generalmente es un sustantivo que no puede aparecer actualizado por el artículo en caso alguno, si no es por especificaciones anafóricas: /Fuimos de la casa a la casa*/. Tampoco caben aquí otro tipo de especificaciones determinadoras, cuantificativas o de otra naturaleza: /Fuimos de casa grande en casa grande?*/. Sin embargo ciertos sufijos de la morfología derivativa pueden acceder al lexema: /Fuimos de casona en casona- (-aza/-ita, illa/-ucha)/, o bien/ de barete en barete/de pelotazo en pelotazo/ de orillita a orillita/). La restricción 
más sobresaliente es que no puede darse una alternancia de $\mathrm{L}$ marcado morfológicamente frente a L no marcado morfolôgicamente (/Fuimos de casita en casota?/ de aventurilla en aventura?). Existe una suerte de solidaridad formal imprescindible, que preserva la igualdad formal de los lexemas, pero que no obstaculiza la identidad referencial de los mismos (obsérvese que esto no es aplicable siempre en la estructura $\mathrm{L}+$ pr. + L: /Fuimos pasito a pasito/, pero / Hemos de hablar carita a carita?*/).

b) Hay algunos casos de fijación fraseologizada total o lexicalización, como en los modales de par en par /de hito en hito/ de bote en bote, siempre asignados a los verbos estar o mirar/ver en relación con actantes muy determinados. Uno de estor verbos es el estativo por excelencia, los otros, verbos de percepción y conocimiento que parecen exigir determinaciones modales. Estos tipos de SSPP parten de la complementación de un sintagma prepositivo para convertirse en estructuras lexicalizadas de naturaleza modal. A este respecto es interesante el artículo de Martinell (1984), si bien estudia estructuras de SSNN $\sin$ un transcategorizador prepositivo del tipo $(\mathrm{N}+\mathrm{de}+\mathrm{N}),(\mathrm{N}+\operatorname{Adj}$.$) , y (\mathrm{N}+\mathrm{N})$.

\section{Los subgrupos léxicos repetidos}

En el seno de dicha estructura formal existen subgrupos donde predominan ciertas elecciones léxicas, que constituyen subgrupos léxicos distintos de un mismo SP. Los paradigmas léxicos que hemos encontrado son los siguientes:

2.1 Sustantivos o sustantivados: que remiten a unidades no numéricas de la división cronológica, o bien enumerables de esa división: (cuando, tanto, largo, raro) ya numerables (vez, tarde,...). Es el caso de /Me ocurre de tarde en tardel (Nieva, 1990, 187); /Con lo poquísimo que yo salgo. De largo en largo, para tomar un poco de vapor/ (Nieva, 1988, 228); /Emite, de tanto en tanto, un corto silbido de advertencia/ (Buero, 1983, 214).

2.2 Numerales sustantivados: que remiten a la modalidad de una distribución organizada de elementos: (uno, dos, cuatro...). Son la numeratividad por antonomasia, pero ordenados en SSPP de esta naturaleza establecen un número indefinido de conjuntos, cada uno de ellos conformados por un número definido de elementos. Como en /Mira de uno en uno a todos los presentes/ (Gala, 1986, 70); /Sus figuras, que irán turnándose, aparecerán de una en unal (Olmo, 1986, 44); /Bajé las escaleras de cuatro en cuatro/ (Arniches, 1981, 160); /Entonces íbamos en fila de dos en dos/ (Gala, 1982, 203).

2.3 Sustantivos discontinuos que remiten metonímicamente a la parte (del cuerpo humano) por el todo (el ser humano): (mano, boca, oreja, parte...) (cf. Schwartz-Norman, 1976). Con los dos primeros sustantivos hay indeterminación 
numérica y preposición nexual en. Con los dos últimos, por contra, hay determinación numérica presupuesta bipolarmente en el seno de un referido conjuntístico, y preposición nexual a (de oreja a orejalde parte a parte). Así en /La pistola anduvo de mano en mano minutos antes de ser disparada/ (Moncada, 1972, 55); /Va de boca en boca lo que digo/ (Martín Recuerda, 1981, 281); /-¿La traspasó? -De parte a partel (Arniches, 1991, 105).

2.4 Sustantivos discontinuos definidos numéricamente en torno a 2; no son pertinentes aquí las partes, sino los todos individualizados y humanos con las mismas características referenciales: (hombre, mujer, compañero, igual...) Caben, por tanto sustantivos genéricos y adjetivos de grupos profesionales, de nacionalidad, procedencia étnica (aunque estos más raramente), de grupos religiosos y políticos e ideológicos (/de colega a colega/, /de igual a igual/), y según puede intuirse, también sustantivos y adjetivos de características morales y anímicas, o clasificadores sociales (Bosque, 1989:108-110). Véanse estos ejemplos: /Ahora respóndeme lealmente, de mujer a mujer/(Casona, 1988, 136); /Parmeno es un amigo, Calixto, y te habla de hombre a hombre/ (Sastre, 1990a, 205); /-Y llevas dentro el miedo y no vas de igual a igual.../ (Sastre, 1971, 58).

\subsection{Sustantivos discontinuos de naturaleza local:}

a) que enfatizan el número indeterminado de elementos, y emplea para ello la preposición nexual en: (banca, feria, calle, risco, habitación, cárcel, bar, corte, ciudad...); así en /Llévame de feria en feria/ (García Lorca, 1990b, 153); /El zagal ha venido gritándolo de risco en riscol (Nieva, 1990, 134); / Y ya nos veíamos allí, nos íbamos de bar en bar/ (Romaní, 1983, 73);

b) que enfatizan el espacio de intermediación entre dos elementos liminares: (orilla, escena, puerta, punta, elemento, oca...) y utiliza para ello la preposición nexual $a$. De este modo en: /Tarzán no tenía otro remedio que cruzar de orilla a orilla/ (Calvo Sotelo, 1967, 37); /España la he recorrido de incógnito, de punta a punta/ (Sánchez-Ventura, 1973, 84); /De oca a oca y tiro porque me.../ (Alonso Millán, 1975, 9).

2.6 Sustantivos discontinuos y eventivos vistos como objetos de naturaleza local y/o espacial, que sólo emplean la preposición nexual en, y que responden a una suerte de metáfora del tipo «un acontecimiento es un lugar o un punto en el tiempo»: (éxito, triunfo, asombro, aventura, recuerdo...) (Lakoff/Johnson, 1980/ 1986). Como en estos enunciados: /Ha corrido usted de aventura en aventura/ (Jardiel Poncela, 1973, 802); ¿QQué es de tu vida? - Va de asombro en asombro/ (Luca de Tena, 1970,36); /Os conduciré de triunfo en triunfo hasta que expulsemos al español/ (Cuevas, 1972, 106); /Dios quiera que la ofensiva de Bilbao no nos lleve, de fracaso en fracaso, a la defensa de Estella/ (Sánchez-Ventura, 1973, 56). 
Por lo anterior, el único de los grupos léxicos que permite una conmutación preposicional entre $a$ y en es el de los sustantivos discontinuos de naturaleza local. El grupo de (orilla, escena, puerta, elemento...) permite la sustitución de a por en, lo cual supone un cambio semántico correlativo, hacia una cuantificación indeterminada. El grupo de (banca, feria, calle, risco, habitación, cárcel, bar, corte, ciudad...) permite la sustitución de en por a, lo cual representa un cambio en la semántica de la cuantificación enunciativa, hacia la restricción numérica en torno a 2. Por contra el grupo de (éxito, triunfo, asombro, sorpresa...) parece no permitir la sustitución fácilmente (¿restricciones distribucionales a causa de su origen metafórico?), así como tampoco el relacionado con la estructura básica del turno de habla, que incluye a sustantivos referidos a los dos polos equiparados de la conversación (hombre, mujer, igual, etc.).

Mientras la conmutación es sensible al sentido, la distribución procura ignorarlo y sus resultados no tienen por qué coincidir (López, 1990: 186). En este sintagma la conmutación muestra que ciertos grupos léxicos son sensibles a la oposición semántica entre la numeratividad determinada (explicitada por a) y la indeterminada (marcada por en). La distribución, por contra, muestra simplemente que existe dicha posibilidad estructural (alternancia funcional entre a/en) o que no la hay para ciertos grupos léxicos.

Aquello que permite hablar de funciones de la repetición léxica en español es justamente el hecho de que en esta lengua, y en particular en este sintagma, la repetición léxica exige la distinción referencial. De otro modo: la explicitación de dos signos idénticos en un mismo sintagma implica dos valores simbólicos iguales en la forma y distintos en la identidad de sus referentes.

De otro lado, no parece haber dudas sobre la función enunciativa de los sintagmas aquí estudiados. Como indica Martínez (1981: 505) puede afirmarse que los sustantivos o las unidades sustantivadas- y aun los adjetivos- necesitan de preposición para funcionar como aditamentos. Esto es extensible a los casos ya vistos de repetición léxica de estructura (pr. $+\mathrm{L}+\mathrm{pr} .+\mathrm{L}$ ). Pero lo esencial no es determinar su función sintáctica, sino establecer sus posibles relaciones con la cuantificación enunciativa, en virtud de la repetición sígnica, que no referencial.

En este sentido, nuestra hipótesis ha de basarse en que la semántica de sustantivos discontinuos se organiza sintácticamente en ciertas estructuras prepositivas isolexemáticas, como la que nos ocupa, estableciendo mediante la preposición nexual, si la pluralidad del enunciado es 2 o es superior a dos. En el caso de los numerales y de los cronológicos indeterminados, con una preposición obligatoria / en/, la discontinuidad del lexema repetido se transforma en continuidad extendida a todo el enunciado, tan sólo limitada por especificaciones del todo que no suelen producirse: (Pasaron de tres en tres/Pasaron todos de tres en tres/Pasaron los tres mil hombres de tres en tres?). Esta numeratividad está implícita en la obligatoriedad de la preposición nexual (/Pasaron de tres a tres\#/Vinieron de cinco a cinco\#/). 
Si, por contra la discontinuidad se marca mediante la preposición a, las relaciones parte/todo se reducen a una modalidad en donde prima la limitación a 2 del lexema repetido. (Cruzó de orilla a orilla /Fue de puerta a puerta/ Hablaron de hombre a hombre).

Parece necesario aclarar que suponemos una correlación entre ciertos tipos de repetición léxica en español y el dominio de la distribución, la cuantificación determinada e indeterminada y el aspecto durativo o progresivo. Es de suponer que tales categorías (o categorizadores) atañen al nivel semántico que se proyecta especialmente sobre ciertas clases de palabras y no sobre otras. Como se ha visto en los ejemplos arriba reseñados, el SP que nos ocupa tiende a aparecer en enunciados con verbos de movimiento (ir, llevar, pasar, traspasar, andar, bajar, entrar) y en cualquier caso activos, lo cual les hace especialmente idóneos para las especificaciones locales distribuidas de distintos referentes.

\section{II.- EL SINTAGMA $\operatorname{Pr}+\mathrm{L}+\mathrm{y}+\mathrm{L}$ (entre copa y copa)}

\section{Restricción léxica de (entre $+L+Y+L)$}

Existe, probablemente un paradigma muy extenso para esta estructura, que permite incorporar partes del cuerpo humano, nombres comunes de la espacialidad, e incluso sustantivos de acción, y no permite repeticiones léxicas relativas a la división cronológica: /entre hoy y hoy*/, /entre hora y hora?*/. Existirá, pues, otra restricción léxica insalvable: la de las partes no especificadas del trascurso temporal. Véase que aquí sólo es posible el aislamiento léxico con la marca de pluralización: /entre horas/, a veces es agramatical: /entre hoyes*/, y generalmente debe acudirse a la distinción léxico-referencial: /entre hoy y mañana/, / entre ayer y hoy/, etc. Cuando se produce la repetición léxica de signos cronológicos resulta imprescindible una determinación añadida:/entre las seis de hoy y las seis de mañanal. Advierte Bosque que uno de los criterios formales más aceptados para distinguir entre sustantivos colectivos y singulares es este:

«Si un sustantivo no coordinado y en singular constituye el término de la preposición entre, será colectivo» (Bosque, 1983: 86)

Lo anterior supone que en efecto, sustantivos colectivos como público, vecindario, juventud, tripulación, equipaje, pareja, maleza, ejército, arboleda, clero, muchedumbre, aristocracia son colectivos, pero no lo serían bosque, archipiélago, prójimo, matrimonio, enjambre, etc.

Por lo que a nuestra estructura se refiere, parece comprobarse que son los sustantivos singulares los que establecen paradigmas léxicos en la repetición, pero la inclusión de sustantivos considerados, por estas y otras pruebas, colectivos, no parece en absoluto imposible, a pesar de su anormalidad: /vivió entre vecindario y vecindario/,/Cayó entre ejército y ejército/, /Se hizo la casa 
entre bosque y bosque/, /Fue feliz entre matrimonio y matrimonio/. Lo importante no parece pues, la naturaleza singular o colectiva del lexema, sino el hecho de que funcione como singular en una estructura que remite a una colectividad obligatoria. Lo único que parece relevante es que se trate de sustantivos discontinuos.

Concluye Bosque (1983:88), que no existe una correlación constante entre los significados léxicos y los comportamientos sintácticos uniformes. Para él han de ser las pruebas formales las que ayuden a clasificar y delimitar las unidades de la gramática. En el caso anterior las pruebas formales no ayudan a delimitar las unidades de la gramática en cuanto a la división entre sustantivos singulares y colectivos.

2. Por lo que hace a durante $L y L$ la situación no es exactamente paralela a la de entre $L$ y $L$. Se permiten lexemas no repetidos (durante horas/minutos/segundos), o deben determinarse mediante artículos demostrativos SSPP o cláusulas de relativo si se hallan en singular: /durante la noche/, Durante este año/,/Durante el tiempo de la siembra/. L debe estar obligatoriamente pluralizado. En realidad entre exige una polaridad que puede entenderse como prolongada, mientras que durante sólo presupone una continuidad que puede fragmentarse. De otro lado el criterio de la eliminación nos advierte que, por más que se trate de un SP, no nos encontramos aquí ante otra variante del mismo grupo funcional: /Durante horas y horas/ resulta tan gramatical como/Durante horas/, de modo paralelo a como/Subía y subia/ lo es respecto a /Subía/. La exigencia morfológica de que $\mathrm{L}$ aparezca solamente en singular delimita el campo de los SSPP repetidos frente a los sintagmas enfatizados por coordinación y yuxtaposición. Incluso en los casos de traslación categorial, debe mantenerse dicha exigencia de la singularidad de los sustantivos, sin perjuicio de que el número de otros determinantes aporten tal información. Tal es el caso de la sustantivación de /auténticos cuerpo a cuerpo/.

Es de notar, por otro lado, que Martínez García (1981:507) advirtió que, en efecto, los sustantivos «temporales» podían también funcionar como aditamento sin preposición, siempre y cuando formaran grupo internamente trabado por solidaridad. Dicha solidaridad puede expresarse mediante la coordinación copulativa (/He escrito horas y horas sin parar/ (isolexemática); /La vigilan día y noche/ (heterolexemática), pero también mediante otros conectores de caracter preposicional, que se estudian a continuación.

\section{III.- EL SINTAGMA L + prep. + L (punto por punto)}

\section{Lexicalización modal del sintagma}

Antes de abordar la descripción paradigmática, es necesario deslindar aquellos sintagmas que han sufrido lexicalizaciones completas, configurándose como 
circunstantes modales, locuciones prepositivas fijas e incluso como interjecciones reduplicadas, sin posibilidad en la elección léxica ni en la traslación funcional.

a) Es el caso de algún cuantificador, como poco a poco: /Me dejé convencer poco a poco/ (Neville, 1990, 170), pero no /me dejé convencer mucho a mucho*/, /bastante a bastante*/. Similares son los casos de hoy por hoy:/Hoy por hoy, el chocolate empieza a ser subversivo/ (Olmo, 1990, 345). Pero no mañana por mañana*, o ayer por ayer*. También alguna interjección puede incorporarse a la nómina de sintagmas lexicalizados, como /ole con ole/: /Se derrumban los castillos, ole con ole, con ole y olé/ (Martín Recuerda, 1988, 159), pero resulta impensable otra reduplicación interjectiva, como/caramba con caramba*/,/vaya con vaya*/o similares.

b) Mientras frente a frente es sintagma de estructura $\mathrm{L}+\mathrm{pr}$. + L y función de complemento circunstancial modal, similar a cara a cara, mano a mano, codo con codo o cuerpo a cuerpo (Bosque 1985:95), que luego se analizarán, el grupo (frente por frente a/de L) es una estructura fijada del paradigma de las preposiciones: introduce un sintagma preposicional locativo, o término, con lo cual se distancia de sus correlatos lexicalizados de bote en bote, de par en par o de hito en hito, los cuales actuaban funcionalmente sin término, como auténticos complementos modales que rayan la lexicalización completa. Para Gaatone (1976) nos encontraríamos ante una locución prepositiva. Debe ser eliminada, consecuentemente, de la nómina de los sintagmas que nos ocupan.

c) al contrario de lo que sucedía en el sintagma de uno en uno, que inducía una numeratividad organizada en el seno de un conjunto no especificado, el sintagma uno a uno, no aparece en español sino como remitente a ciertas organizaciones numéricas de núcleo elidido. Esto supone que el sintagma no permite juego léxico con los numerales: /Le señala, una por una, todas las prendas/ (Olmo, 1990, 137), pero no /dos a dos*, cinco a cinco*, etc./, / $\mathrm{Y}$ todos dijeron lo mismo?, - Uno por uno/ (Benavente, 1988, 72), y nunca cinco por cinco*, o dos por $d o s^{*}$. Las repeticiones léxicas prepositivas que no deben entrar en este paradigma general de $(\mathrm{L}+$ prep. $+\mathrm{L})$ son, aparte de las ya reseñadas, las configuradas en torno a elisiones de núcleos nominales, como /El Madrid y el Barcelona quedaron dos $(\varnothing)$ a dos $(\varnothing) /$, donde $\emptyset$ equivale a /goles, puntos, tantos, etc./, pero tanto en la coincidencia lexemática como fuera de ella.

La lexicalización general de los sintagmas anteriores tiene una comprobación añadida: resultan infinitamente más frecuentes en los enunciados del español que los sintagmas formalmente similares que inducen valores de numeratividad indeterminada, y que a continuación se describen. 


\section{La estructura formal de $(L+p r+L)$}

\subsection{La naturaleza del nexo prepositivo.}

Ya en el estudio del paradigma productivo, las posibilidades de variación del nexo presupositivo son sin duda mayores que las propias del sintagma (prep. $+\mathrm{L}$ + prep. + L). Nuestro corpus encuentra, para la categoría sustantiva, un juego prepositivo en torno a con/a/por/sobre/tras/, es decir, preposiciones que marcan la igualdad (a/con), o su relación sucesiva (por/sobre/tras). Como era de esperar, en los casos de lexicalización como los analizados antes, no puede hablarse más que de obligatoriedad del nexo prepositivo ( $a$, para el cuantificador poco y el numeral uno; con, para la interjección ole; por para la locución prepositiva frente por frente de L) (López, 1990).

\subsection{Los tipos de nombres comunes en $(\mathrm{L}+$ pre $+\mathrm{L})$.}

los sustantivos que configuran el sintagma $(\mathrm{L}+$ prep. $+\mathrm{L})$ remiten a algunos de los tipos hallados en el sintagma (prep. $+\mathrm{L}+$ prep. $+\mathrm{L}$ ). Se describen a continuación:

\subsubsection{Relaciones metonímicas de partes del cuerpo humano para la explicitación} de los individuos implicados, en el plano de la igualdad activa: /Conque nos sentamos mano a mano, y nos sirven una ensalá/ (Arniches, 1981, 71); /El campo de batalla va entre lineas- lectores y noticia frente a frente/ (Olmo, 1990, 241); /El numantino combate cuerpo a cuerpo/ (Sastre, 1990, 393). En ocasiones las partes restituyen la integridad de un mismo todo, siempre con valor modal: $/ \mathrm{iEl}$ reo! Los brazos atados codo con codo/ (Rodríguez Méndez, 1986, 118). En estos y otros casos que pudieran aducirse, los nexos prepositivos son relacionales puros o estáticos, y existe una determinación numérica en torno a dos, que tienden a reintegrar la unidad o la unión entre los iguales.

2.2.2. Relaciones de sucesión de las partes numéricamente indeterminadas. Aquí entran, en primer lugar, los sustantivos discontinuos de carácter cronológico, que clasifican ordenadamente el discurso del tiempo hasta la reintegración explicitada (o presupuesta) de todo el conjunto: /Los he ido reconstruyendo, los hechos, minuto a minuto/ (Salom, 1972, 69); / Has pensado en que te estás humillando hora a hora?/ (Armiñán, 1968, 63); /Te juro que te sentirás liberada, día tras día, de este infierno en que vives/ (Martín Recuerda, 1981, 118). En segundo lugar, se encuentran los sustantivos discontinuos no cronológicos que configuran partes expuestas en sucesión temporal de un todo conformado por un número indeterminado de miembros. Es este el subgrupo más numeroso, algunos de cuyos representantes se reseñan en lo que sigue: /Yo me comeré esa granada grano a grano/ (Sastre, 1990,393); /¿Y de mí, que le dediqué soneto tras soneto 
como al más noble señor?/ (Benavente, 1988, 112); ¿Para qué la querría usted (la iglesia)? -Para llevármela piedra a piedral (Calvo Sotelo, 1967, 46); /Senén seguirá, punto por punto, el plan que se ha trazado/(Herrero, 1986, 73); /Durante cuatro años hemos perdido batalla tras batalla/ (Cuevas, 1972, 94).

Como se ve, el todo no es explícito en sí mismo respecto al número, pero pueden explicitarse sus partes sin atender al número de sus componentes. El sintagma, además, puede inducir simplemente la información del todo, en cuyo caso hemos de hablar de un activador presupositivo, como en /Yo recuerdo casi palabra por palabral (Paso, 1965, 88), donde la reintegración del todo (el discurso, la conversación, el acto de habla en suma) se produce por una inferencia del oyente. (Wierbicka, 1986), o bien por una relación anafórica.

\subsection{Traslaciones funcionales y correlaciones de categorias}

1.- La estructura $(\mathrm{L}+$ prep. $+\mathrm{L})$ es sensible a traslaciones funcionales vedadas al sintagma (prep. $+\mathrm{L}+$ prep. $+\mathrm{L}$ ). Esto le permite actuar como un núcleo nominal, pero sometido a restricciones morfológicas severas: /La comisión de televisión suele deparar auténticos cuerpo a cuerpo entre el director general y la oposición/ (El País, 26-2-1992), pero /auténticos cuerpos a cuerpos $\%$. De modo que la pluralización viene rellenada por la determinación adjetiva, de manera paralela a la marca de género en ciertos sustantivos invariables en su forma interna: /la crisis-las crisis/. El encabezamiento prepositivo actúa como inhibidor de ciertas traslaciones funcionales, y el nexo interno puede acceder a dichas traslaciones siempre que no contravenga su fijación interna.

2.- Por lo que respecta a la existencia de correlaciones léxicas entre los sustantivos de este sintagma y las categorías verbal y nominal, resulta que los núcleos repetidos en estructuras lexicalizadas (uno, nada, ole, frente, entre otros), tienen vetado un acceso morfológico directo a la categoría verbal. De hacerlo, suelen requerir estructuras parasintéticas, como anonadar, enfrentar, apocar apoquinar(se), aunar. Por contra, muchos de los sustantivos del sintagma no lexicalizado conocen verbalizaciones y nominalizaciones mediante el sufijo aspectual frecuentativo -e-. Es el caso de punto/punto por puntolpuntear/punteo; paso a pasolpasear/paseo; minuto/minuto a minuto/minutear/minuteo; caral cara a cara/careo. Tales modificaciones morfológicas, muy productivas en el español de América (Morales, Quiroz y Mayorga, 1969, Montes Giraldo, 1983, 1985), son sin duda posibles a partir de valores aspectuales de la repetición indeterminada o frecuentatividad, que es, por otra parte, lo que defendemos para la repetición léxica en este tipo de sintagmas prepositivos. 


\section{Una definición funcional del sintagma $(L+$ prep. $+L)$}

La estructura $\mathrm{L}+\mathrm{pr}+\mathrm{L}$ con núcleos nominales isolexemáticos, exige nombres comunes discontinuos y que establecen relaciones con las bases perceptivas de la parte y el todo. Son sensibles a la traslación categorial y funcional, pero con restricciones morfológicas impuestas desde su constitución interna semi-fraseologizada. En esto se oponen a otras formas isolexemáticas engarzadas preposicionalmente, como ( $\mathrm{pr}+\mathrm{L}+\mathrm{pr}+\mathrm{L}$ ) y también $(\mathrm{pr}+\mathrm{L}+\mathrm{y}+$ L), que no pueden acceder a otras funciones típicamente nominales. De otro lado, tienden a escoger sustantivos relativos a las partes del cuerpo humano, de la configuración de los objetos, de la división cronológica no numérica y de la espacialidad, pero tienen vetados los numerales. Remite a una modalización numérica indeterminada, igualitaria o sucesiva.

\section{Algunas notas para el estudio de la estructura $L+y$ (o yuxtaposición $)+L)$}

Las estructuras hasta aquí estudiadas son internamente integradas: los elementos que las constituyen no pueden eliminarse en algún extremo sin provocar la agramaticalidad del enunciado o la incorrección constructiva. Así / Se vieron cara a cara/ pero no /Se vieron cara*/; /Lo recuerdo palabra por palabra/ pero no /Lo recuerdo palabra*/; /Crecía de hora en hora/, pero no /Crecía de hora*/; /Hablaron entre cigarro y cigarro/, pero no/Hablaron entre cigarro*/. Por contra, la repetición léxica que ahora es objeto de nuestra atención y que formalmente exige una coordinación copulativa o yuxtapuesta, puede eliminar uno de los dos miembros coordinados sin que el enunciado se resienta sintácticamente (una prueba de su menor integración funcional), y apenas lo haga semánticamente.

Además, la repetición de estructuras copulativas y yuxtapuestas engloba a casi todas las categorías mayores del español, mientras que la sintaxis prepositiva exigía al sustantivo o la sustantivación de otras categorías.

Encontramos entonces sustantivos coordinados o yuxtapuestos, como /Pues por todas partes encontrarán timbres y timbres/ (Celaya, 1972, 49); adverbios cuantificadores, como en /El golperío suena más y más por todas partes/ (Martín Recuerda, 1988,271); verbos activos procesuales o durativos: /El timbre sonaba y sonaba/ (Rodríguez Méndez, 1986, 125); de movimiento: /Desciendo y desciendo por las profundidades de tu alma/ (Riaza, 1982, 148); de habla: /Don Sacramento habla y habla con la retórica intransigente que nada puede ofrecer/ (Mihura, 1990, 139); prefijados con re-o con des-en el segundo de sus núcleos: /Leía y releía el mensaje/ (Castillo Puche, 1983, 220); /Las gaviotas hacian y deshacián en el cielo un techo de alas/ (Cunqueiro, 1981, 119); adjetivos en función atributiva: /A mí me gusta ver correr lleno de lumbre lo que está quieto y quieto años enteros/(García Lorca, 1987, 185); incluso interjecciones:/-Tenías una alergia a los tranvías! En cuanto me subía en el 17, ya estabas pumba, pumba. Y yo te decía: «Ya está Quincoces...»/(Paso, 1965, 560). 
No son posibles repeticiones léxicas de las llamadas partículas de relación, al contrario de lo que sucede en inglés según Knowles (1979). Ni el artículo, ni la conjunción, ni la preposición (salvo en raros casos de lexicalización ya comentados) puede coordinarse en español.

Sin entrar en el análisis funcional de esquema tan poco integrado, pero tan variable como lo permitan sus núcleos léxicos, relacionados con la duración, progresión o la cantidad, intentaramos establecer la hipótesis de que, en lugar de organizar formalmente la distribución referencial, su función es directamente icónica, en el sentido de que a mayor cantidad sígnica debiera corresponderle una intensificación de lo referido. Si aceptamos lo anterior (que está por comprobar) deberíamos concluir que el posible iconismo de las repeticiones léxicas con sintaxis prepositiva del español existe encubierto hacia una determinación sintáctica que permite la distribución. Así las cosas, podrían propugnarse para esta lengua, dos tipos de estructuras isolexemáticas:

a) Estructuras isolexemáticas de la distribución. Están integradas sintácticamente; remiten a una gramática de la parte y el todo; permiten un cierto juego paradigmático en sus nexos; tienden a escoger sustantivos discontinuos cronológicos, personales, anatómicos y espaciales. Sus funciones básicas son las de establecer especificaciones modales en el enunciado en lo relativo a la numeratividad indeterminada, y a la determinada en torno a dos elementos. Actúan como complementos adverbiales eliminables (si tomados en su totalidad) las más de las veces. Resulta esencial a su idiosincrasia el mantener la identidad referencial de sus signos idénticos, cuya cohesión, sin embargo, remite siempre a más de un referente. La distribución isolexemática es específicamente nominal.

b) Estructuras isolexemáticas de la intensificación. No están integrados sintácticamente (no son nucleares en su totalidad). Exigen una sintaxis de la coordinación copulativa y la yuxtapuesta, y nunca prepositiva. No permiten juego paradigmático alguno de sus nexos, pero uno de sus miembros (y el nexo, al tiempo) puede ser eliminado sin peligro de agramaticalidad. No sólo escogen sustantivos discontinuos cronológicos, de partes del cuerpo humano, personales y espaciales, sino también cuantificadores, adjetivos, adverbios, interjecciones y especialmente verbos activos de carácter atélico (generalmente procesuales), que engloban tanto a los de movimiento, como los de habla, los de percepción y conocimiento y los meteorológicos. La intensificación isolexemática afecta a todas las categorías plenas.

Son estas, consideraciones que no responden a un estudio sistemático sobre la repetición léxica coordinada y yuxtapuesta, pero que sirven como hipótesis parcialmente refrendada para el inglés por Knowles (1979), para el francés por Shapira (1988) y, en menor medida, por Frédéric (1985), para el italiano por 
Wierbicka (1986), y en una gran cantidad de lenguas por Greenberg (1978) y Moravcsic (1978), en relación con la cuantificación y la intensificación por medio de la repetición léxica. De modo muy perspicaz, Escandell (1991) ha estudiado las «reduplicaciones léxicas» de las yuxtaposiciones y de las coordinaciones, especialmente en las categorías verbal y nominal. Atribuye a la coordinación una acumulación de referentes en el caso de los nombres, y una cumulación de extensión o iteración en el caso de los verbos, según su aspecto. Sería de desear que sus agudas observaciones sobre nombres y verbos casaran igualmente con el comportamiento de adjetivos, adverbios, cuantificadores e interjecciones.

\section{FUENTES DEL CORPUS DE ORACIONES}

Tan sólo se especifica aquí el año de la edición consultada, y no el de la edición original de cada obra.

ALONSO MILlÁN, J. J. (1975), Cantando se entiende la gente. ¿A que nos quitan lo bailao...?, Madrid, Escelicer.

ARMIÑ́́N, J. (1968), Una vez a la semana, Madrid, Escelicer.

ARNICHES, C. (1981), Del Madrid castizo, ed.: Moreno Padilla, Madrid, Cátedra.

BENA VENTE, J. (1988), Los intereses creados, ed.: Lázaro Carreter, Madrid, Cátedra.

BUERO VALLEJO, A. (1983), La tejedora de sueños. Llegada de los dioses, ed.: Iglesias

Feijoo, Madrid, Cátedra.

CALVO SOTELO, J. (1967), El baño de las ninfas, Madrid, Escelicer.

CASONA, A. (1988), La dama del alba, ed.: Rodríguez Guitart, Madrid, Cátedra.

CASTILLO PUCHE, J. L. (1983), Sin camino, Barcelona, Destino.

CELAYA, G. (1972), El relevo, Madrid, Escelicer.

CUEVAS, F. (1972) Edipo libertador, Madrid, Escelicer.

CUNQUEIRO, A. (1981), Un hombre que se parecía a Orestes, Barcelona, Destino.

GALA, A. (1982) Noviembre y un poco de yerba. Petra Regalada, ed.: Zatling Boring, Madrid, Cátedra.

GALA, A. (1986), Samarcanda, Madrid, Antonio Machado Ed.

GARCIA LORCA, F. (1987), La casa de Bernarda Alba, ed.: Josephs y Caballero, Madrid, Cátedra.

- (1990), Bodas de sangre, ed.: Josephs y Caballero, Madrid, Cátedra.

HERRERO, P. M. (1986), El homenaje, Madrid, Ediciones MK.

JARDIEL PONCELA, E. (1973), Obras completas, v. IV, Barcelona, Ed. AHR.

LUCA DE TENA, J. I. (1970), ¿Quién soy yo? y Yo soy Brandel, Madrid, Escelicer.

MARTÍN RECUERDA, J. (1981), El engañao. Caballos desbocaos, ed.: Halsey y Cobo, Madrid, Cátedra.

- (1988), Las salvajes en puente San Gil Las arrecogías del beaterio de Santa María Egipcíaca, ed.: Ruiz Ramón, Madrid, Cátedra.

MIHURA, M. (1990), Tres sombreros de copa, ed.: Rodríguez Padrón, Madrid, Cátedra. MONCADA, S. (1972), Juegos de medianoche, Madrid, Escelicer.

NEVILLE, E. (1990), El baile la vida en un hilo, ed.: Burguera, Madrid, Cátedra.

NIEVA, F. (1988), Trilogía italiana, ed.: Barrajón, Madrid, Cátedra.

- (1990), Malditas sean Coronada y sus hijas. Delirio del amor hostil, ed.: González, Madrid, Cátedra. 
OLMO; L. (1986), Pablo Iglesias, Madrid, Ed. Antonio Machado.

- (1990), La camisa. El cuarto poder, ed.: Berenguer, Madrid, Cátedra.

PASO, A. (1965), Cita a los veinticinco años, Madrid, Escelicer.

RIAZA, L. (1982), El desván de los machos y el sótano de las hembras. El palacio de los monos, ed.: Castilla y Riaza, Madrid, Cátedra.

RODRÍGUEZ MÉNDEZ, J. M. (1986), Bodas que fueron famosas del Pingajo y la Fandanga. Flor de Otoño, ed.: Martín Recuerda, Madrid, Cátedra.

ROMANÍ, O. (1983), A tumba abierta. Autobiografia de un grifota, Barcelona, Anagrama.

SALOM, J. (1972), La noche de los cien pájaros, Madrid, Escelicer.

SÁNCHEZ VENTURA, F. (1973), Volveré, Madrid, Escelicer.

SASTRE, A. (1971), Muerte en el barrio, Madrid, Escelicer.

- (1990), La taberna fantástica. Taberna fantástica de la gitana Celestina., ed.: M. de Paco, Madrid, Cátedra.

\section{BIBLIOGRAFIA}

BEINHAUER, H. (1964/1985), El español coloquial, Madrid, Gredos.

BERNÁRDEZ, E. (1982), Introducción a la lingüística del texto, Madrid, Espasa-Calpe. BOSQUE, I. (1980), Sobre la negación, Madrid, Cátedra.

- (1983a), «Clases de nombres comunes», en Serta Philologica F. Lázaro Carreter,

I, Madrid, Cátedra, 77-88.

- (1983b), «El complemento del adjetivo», LEA, V/I, 1-15.

- (1985), «Sobre las oraciones recíprocas en español», Revista Española de Lingüística,

(R. S. E. L)., 59-96.

- (1989), Las categorías gramaticales. Relaciones y diferencias, Madrid, Síntesis.

FRÉDÉRIC, M. (1985) La répétition. Étude linguistique et rhétorique, Tübingen, Max Niemeyer.

GAATONE, D. (1976), «Locutions prépositives et groupes prépositionnels»,Linguistics, $167,15-33$.

GIL, D. (1988), «Georgian reduplication and the domain of distributivity», Linguistic $s, 26$, 1039-65.

GONZÁLEZ OLLÉ, F. (1979), «La negación expresiva mediante la oposición sintagmática de género gramatical: el tipo sin dineros ni dineras y sus variantes», en Geckeler/ Schlieben-Lange/Trabant/Weidt (eds.): Logos semantikos: Studia linguistica in honorem Eugenio Coseriu, 1921-1981, 215-37.

GREENBERG, J. H. (1978), «Generalizations about numeral systems», en Greenberg (ed.): Universals of Human Language, v. 3, 149-295.

KNOWLES, J. (1979), «Lexemic iteration», Linguistics, 641-57.

LAKOFF, G. Y JOHNSON, M. (1980/1986), Metáforas de la vida cotidiana, Madrid, Cátedra.

LÓPEZ GARCÍA-MOLÍNS, (1984/1990), «La estructura formal del modismo», en Nuevos estudios de lingüística española, Universidad de Murcia, 193-205.

- (1990), «El sistema prepositivo español», en Nuevos estudios de lingüĺstica española, Universidad de Murcia, 169-91.

MANTECA ALONSO-CORTÉS, (1987), Lingüística general, Madrid, Cátedra.

MARTINELL, E., (1984), «De la complementación a la composición en el sintagma nominal», Revista Española de Lingǘística, (R. S. E. L)., 14-2, pp. 23-44.

MARTÍNEZ GARCÍA, H., (1988), «Sobre la rección y el régimen preposicional», Archivum, 37-38, pp. 75-87.

MARTÍNEZ, E. (1981), «Acerca de la trasposición y el aditamento sin preposición», Archivum, 31-32, pp. 493-512.

MCLAUGHLIN, M. (1984), Conversation, Beverly Hills, Sage Publications. 
MONTES GIRALDO, J. J.,(1983), Motivación y creación léxica en el español de Colombia, Bogotá, BICC.

- (1985), Estudios sobre el español de Colombia, Bogotá, BICC.

MORALES, F., QUIROZ, O. Y MAYORGA, D., (1969), Los verbos en -ear-en el español de Chile, Santiago de Chile, Editorial del Pacífico.

MORAVCSIK, E. A. (1978), «Reduplicative constructions», en Greenberg (ed.): Universals of Human Language, v. 3, 297-334.

MORERA PÉREZ, M. (1988), Estructura semántica del sistema preposicional del español y sus campos de uso, Puerto del Rosario, Exmo. Cabildo Insular de Fuenteventura.

PHARIES, D. A. (1983), «Expressive word-formation in Spanish: the cases of titiritar 'tremble', pipiritaña 'cane flute', etc.», Romance Philology, XXXVI, 347-65.

SCHWARZ-NORMAN, L. (1976), «The grammar of 'content' and 'container'», Journal of Linguistics, 2, 279-87.

SHAPIRA, C. (1988), «Le redoublement expressif dans la création lexicale», Cahiers de Lexicologie, 52, 51-63.

WIERZBICKA, (1986), «Italian reduplication: cross-cultural pragmatics and illocutionary semantics», Linguistics, 24, 287-315. 